\title{
SIMONE BERNARD-GRIFFITHS, Essais sur l'imaginaire de George Sand
}

\section{Lise Sabourin}

\section{(2) OpenEdition}

\section{Journals}

\section{Édition électronique}

URL : https://journals.openedition.org/studifrancesi/44049

DOI : $10.4000 /$ studifrancesi.44049

ISSN : 2427-5856

\section{Éditeur}

Rosenberg \& Sellier

\section{Édition imprimée}

Date de publication : 1 juin 2021

Pagination : 229-230

ISSN : 0039-2944

\section{Référence électronique}

Lise Sabourin, " Simone bernard-GrifFIths, Essais sur l'imaginaire de George Sand », Studi Francesi [En ligne], $193($ LXV | I) | 2021, mis en ligne le 01 juillet 2021, consulté le 15 octobre 2022. URL : http:// journals.openedition.org/studifrancesi/44049; DOI : https://doi.org/10.4000/studifrancesi.44049

Ce document a été généré automatiquement le 15 octobre 2022.

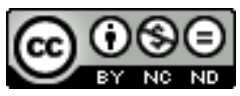

Creative Commons - Attribution - Pas d'Utilisation Commerciale - Pas de Modification 4.0 International - CC BY-NC-ND 4.0

https://creativecommons.org/licenses/by-nc-nd/4.0/ 


\title{
SIMONE BERNARD-GRIFFITHS, Essais sur l'imaginaire de George Sand
}

\author{
Lise Sabourin
}

\section{RÉFÉRENCE}

SIMONE BERNARD-GRIFFITHS, Essais sur l'imaginaire de George Sand, Paris, Classiques Garnier, 2018, 616 pp.

1 La grande spécialiste de l'histoire des représentations et de l'imaginaire qu'est Simone Bernard-Griffiths rassemble dans ce volume ses Essais sur l'imaginaire de George Sand, organisés en trois parties: «Poétique de l'espace» (pp. 69-19), «Représentations sociales et ethnographiques» (pp.197-369) et «Traversée des genres littéraires et des modes d'écriture» (pp. 373-571).

2 La première partie se penche sur le paysage dans La Mare au diable, l'espace dans Nanon, les fleurs et jardins pour Antonia, les volcans auvergnats des Journaux de voyage à Jean de La Roche, le feuilleté entre terre et mer dans la Provence varoise de Tamaris et le palimpseste vénitien dans Mattea.

La deuxième section part d'études sur François le champi et Mauprat pour discerner l'ethnographie poétique des fêtes berrichonnes et le merveilleux des nuits dans l'imaginaire sandien, notamment dans André, La Mare au diable, Claudie, Les Maîtres sonneurs, Le Meunier d'Angibault et les Légendes rustiques.

4 La troisième partie s'intéresse d'abord aux contes des années 1870 (L'Orgue du titan, Le Château de Pictordu, Les Contes d'une grand-mère, La Reine Coax, La Fée poussière et La Fée aux gros yeux), puis remonte aux nouvelles de jeunesse (La Marquise et Metella confrontée à La Femme abandonnée balzacienne), se clôt sur les romans Valentine, Indiana et Jeanne.

5 La préface (pp. 9-67) en donne une belle synthèse que complète l'épilogue (pp. 573-575). La «reine des facultés» se nourrit des rêves de l'enfance aussi bien lors des promenades 
au jardin que par la superposition des lectures légendaires et philosophiques. Aussi Nohant transparaît-il dans le Belair de La Mare au diable par une artialisation du paysage qui s'effectue sur Tamaris comme sur Venise. L'espace devient ainsi personnage, voué à un rôle déterminant dans la structuration diégétique, créant des symboliques antithétiques, parfois oniriques. Mais la création sandienne se nourrit aussi de données ethnographiques, particulièrement bienvenues en cette époque romantique de collation folklorique. Elles s'insinuent subtilement entre coutumes réelles et célébration idéalisée, qu'il s'agisse des fêtes traditionnelles, des noces ou des danses villageoises. Le goût du primitif, lié au fantastique, insuffle la poéticité de la rêverie. Reste à jouer sur les genres, par le détour métaphysique que procurent les contes, mais aussi par la sublimation subjective des histoires vraies. Si la nouvelle incite à «une seule histoire» selon le précepte goethéen, le roman permet, lui, la polyphonie de personnages groupés en duos métapoétiques. Ainsi l'artiste peut-elle être fidèle à sa propre nature, en s'imprégnant de données réelles, sans prétention scientifique, mais en créant un «monde nouveau» personnel par la puissance de son imagination qui, grâce à une observation poétisée, opère en «reine du vrai». 